\title{
Desde el hospicio: la poesía dispersa de Jacobo Fijman y la transformación de su proyecto estético*
}

\author{
From the \\ Psychiatric \\ Hospital: \\ Jacobo Fijman's \\ Dispersed \\ Poetry and the \\ Transformation \\ of his Aesthetic \\ Project
}

Primer semestre de 2020 - pp. 49-62

Segunda época

$N^{0}=1$

\author{
Do hospício: a \\ poesia dispersa \\ de Jacobo Fijman \\ e a transformação \\ de seu projeto \\ estético
}

Enzo Cárcano** Orcid: https://orcid.org/0000-0003-0676-6990

\begin{abstract}
Para citar este artículo
Cárcano, E. (2020). Desde el hospicio: la poesía dispersa de Jacobo Fijman y la transformación de su proyecto estético. Folios, 51, 49-62. doi: 10.17227/folios.51-8536
\end{abstract}

Artículo recibido $08 \cdot 10 \cdot 2018$

Artículo aprobado $25 \cdot 07 \cdot 2019$

* El presente texto constituye una síntesis y ampliación de algunos aspectos abordados en mi tesis doctoral "Con los ojos en la noche": la poesía "mística" de Jacobo Fijman en los márgenes.

** Doctor en Letras de la Universidad del Salvador Buenos Aires, Argentina. Becario posdoctoral del Consejo Nacional de Investigaciones Científicas y Técnicas (Conicet), Instituto de Filología y Literaturas Hispánicas Dr. Amado Alonso, Universidad de Buenos Aires (IFLH, UBA). Profesor de la Universidad del Salvador (usal, Universidad Pedagógica Nacional, Buenos Aires), Argentina.

Correo electrónico: enzo.carcano@usal.edu.ar 


\title{
Resumen
}

El presente artículo, que constituye una continuación de mi investigación sobre la obra de Jacobo Fijman, en buena parte ilustrada en mi tesis doctoral, se propone establecer que la trayectoria lírica del poeta constituye un auténtico proyecto estético marginal, que puede dividirse en dos períodos. El primero abarca la producción que va desde los comienzos hasta la consolidación de lo que llamo la mística fijmaniana. El segundo comprende la poesía — la recuperada hasta hoy—escrita por Fijman durante su internación. En esta época; se advierte una pronunciada deriva del proyecto que había alcanzado en la mística sus rasgos más distintivos. Previo examen de la lírica fijmaniana anterior, propongo aquí un análisis de la vuelta a la referencialidad y la retórica arcaizante como ejes vertebradores de la producción última para caracterizar el modo en el que se transforma el proyecto lírico fijmaniano en los años de la estancia del poeta en el hospicio, que, aunque mutado, sigue respondiendo a un principio estético que reafirma en el margen.

\author{
Palabras clave \\ poesía argentina; Fijman, poesía dispersa; proyecto; mística
}

\begin{abstract}
This article, which constitutes a continuation of my research on the work of Jacobo Fijman, largely illustrated in my doctoral thesis, intends to establish that the poet's lyrical trajectory constitutes an authentic marginal aesthetic project, which can be divided into two periods. The first covers the production that goes from the beginnings until the consolidation of what I call the fijmanian mystics. The second includes poetry - the one collected until today — written by Fijman during his stay in the psychiatric hospital. In this period, it is possible to notice a pronounced transformation of the project that had reached in the mystics its most defining characteristics. In this article, I first examine the previous works, and then I analyze the return to referentiality and the archaizing rhetoric as the distinctive features of the way the fijmanian aesthetic project is transformed during the years the poet spent in the psychiatric hospital.

Keywords

Argentinian poetry; Fijman; dispersed poetry; project; mystic

0 presente artigo, que constitui uma continuação de minha pesquisa sobre o trabalho de Jacobo Fijman, amplamente ilustrado em minha tese de doutorado, pretende estabelecer que a trajetória lírica do poeta constitui um autêntico projeto estético marginal, que pode ser dividido em dois períodos. 0 primeiro abrange a produção que vai do começo até a consolidação do que eu chamo de mística fijmaniana. 0 segundo inclui poesia -a que foi recuperada até hojeescrita por Fijman durante seu internamento. Naquela época houve um desvio acentuado do projeto que alcançou as características mais distintivas da mística. Após examinar a lírica fijmaniana anterior, proponho aqui uma análise do retorno à referencialidade e à retórica arcaica como espinha dorsal da última produção para caracterizar a maneira pela qual o projeto lírico fijmaniano é transformado nos anos de permanência do poeta no hospício, que, embora mudado, continua a responder a um princípio estético que reafirma na margem.
\end{abstract}

Abstract

\section{Resumo}

\section{Palavras-chave}

poesia argentina; Fijman; poesia dispersa; projeto; mística 


\section{Introducción}

La figura de Jacobo Fijman (1898-1970), poeta argentino nacido en territorio de la actual República de Moldavia (otrora, del Imperio Ruso), suele asociarse a su prolongada internación (1942-1970) en el entonces Hospicio de las Mercedes ${ }^{1}$ de la Ciudad de Buenos Aires, consecuencia de un diagnóstico que lo juzgó psicótico ${ }^{2}$. Esta asociación, casi automática en algunos trabajos, también ha marcado en buena medida las consideraciones críticas que ha recibido su obra poética, a menudo tildada linealmente como producto de una mente perturbada o como la confesión de un místico incomprendido. Sin embargo, este tipo de juicios soslayan el carácter notablemente cohesivo que define esta trayectoria lírica como un auténtico proyecto estético marginal ${ }^{3}$, que puede dividirse en dos períodos a grandes rasgos. El primero abarca la producción que va desde los comienzos hasta la consolidación de lo que llamo la mística fijmaniana ${ }^{4}$, e incluye los Versos de juventud (c. 1923) y Molino rojo (1926), considerados la etapa preparativa, así como Hecho de estampas (1929) y Estrella de la mañana (1931), libros en los que se advierte consolidación de ese lenguaje. El

1 El Hospicio de las Mercedes fue inaugurado el 8 de mayo de 1887. Desde entonces, la institución ha cambiado cuatro veces de nombre: en 1949, "Hospital Nacional Neuropsiquiátrico de Hombres"; en 1967, "Hospital Nacional José Tiburcio Borda"; en 1996, "Hospital Neuropsiquiátrico José Tiburcio Borda", y poco después, “Hospital Psicoasistencial Interdisciplinario José Tiburcio Borda". No obstante, estas variaciones, el Hospital fue por años popularmente conocido como el "Vieytes", nombre que llevó la calle en la que se emplaza.

2 De acuerdo con la "Comunicación de la internación" que se transcribe en el número homenaje de Talismán, Fijman fue remitido por la Policía de la Capital Federal al Borda el 2 de noviembre "por hallarse afectado de alienación mental, la que fue diagnosticada de "Psicosis distímica-Síndrome confusional»" (9).

3 Marginalidad deliberada y no, como han sostenido algunos críticos (cfr. Arancet Ruda, 2014, pp. 31-32), salvaje, siguiendo las formulaciones de Jitrik (1998, p. 22).

4 Realizo un estudio sistemático sobre el tema en mi tesis doctoral "Con los ojos en la noche": la poesía "mística" de Jacobo Fijman en los márgenes, de 2017.

5 Sigo la denominación Versos de juventud, propuesta por Alberto A. Arias en su edición. segundo período ${ }^{6}$ se extiende, aproximadamente ${ }^{7}$, desde 1952 hasta 1969, y comprende la poesía —al menos, la recuperada hasta hoy ${ }^{8}$ - escrita por Fijman durante su internación y no publicada como libro. En esta última época, casi desconocida hasta ahora, aunque no menos prolífica que la anterior, se advierte una pronunciada deriva del proyecto que había alcanzado en la mística sus rasgos más distintivos. De la concentración que caracteriza la lengua poética del segundo y el tercer poemario, se percibe ahora una vuelta a la referencialidad, que, aunque difusa, apunta, junto con una retórica arcaizante, a la ponderación de un pasado histórico o legendario. En el presente trabajo, previo examen de la lírica fijmaniana anterior, propongo un análisis de estos dos ejes vertebradores de la producción última para caracterizar el modo en el que se transforma el proyecto en los años de la estancia del poeta en el hospicio.

\section{Hacia la mística}

Con el ánimo de seguir a Michel de Certeau, la mística fue el modo de practicar el lenguaje heredado que distinguió una forma de enfrentar el problema de la relación del hombre con el Absoluto, propia de los espirituales europeos de los siglos XIII al XVII, momento de profundas crisis sociales, políticas e institucionales en el continente. Este modus loquendi (Certeau, 2006), "herido" por el deseo del Otro inaccesible, cobró la forma de un lenguaje de la ausencia, logró su más alto grado de formalización alrededor del siglo xvi con la delimitación de la mística como disciplina autónoma, y se

6 Las piezas "Luminaria mayor", "Luna del sí, sí, y del no, no" y “Letanía del agua perfecta", aparecidas luego del último poemario, entre 1933 y 1934 en La Nación y Arx, pueden considerarse un interregno entre el primer y el segundo período, ya que, si bien guardan relación con el inicial, anuncian las derivas del siguiente.

7 Según sugiere Arias, el año del que presuntamente data la primera composición fijmaniana de la que se tiene noticia luego de la internación del autor, "Canción de la doctora del anillo de jaspe", es, probablemente, un agregado posterior y no una indicación de Fijman mismo (Fijman, 2005, p. 206).

8 Durante su internación, el poeta repartió sus creaciones, muchas veces escritas sobre documentos oficiales descartados, entre médicos, amigos y conocidos, por lo que aún se desconoce el volumen total de la producción fijmaniana, que solo se ha recuperado parcialmente. 
deshizo poco más tarde con el Iluminismo, cuando fue postergado a los márgenes de la racionalidad que se impuso. Al desintegrarse el contexto que la hacía posible, la mística propiamente dicha desapareció. De ella nos llegan todavía hoy rastros, usualmente relacionados con lo extraordinario, que otras disciplinas recogieron (p. 85). De lo señalado hasta aquí se comprende que Certeau desestime la posibilidad de sentenciar la verdad o falsedad - o mejor, la existencia o inexistencia- de una experiencia particular más allá del texto en sí. Independientemente del gran número de escritos que abordan la cuestión de la relación del hombre con lo Otro, aquello que hace que estos puedan ser considerados estrictamente místicos es, además de una formalidad, su anclaje en un contexto sociohistórico determinado. De aquí se deduce que, cuando a propósito de un periodo de la trayectoria poética fijmaniana, hablo de mística, lo hago - como se advierte en el uso de la cursiva - en sentido traslaticio o figurado, ya que, si bien escapa a las coordenadas espaciotemporales que hicieron posible la mística, se trata de un lenguaje lírico que también constituye una apuesta por decir al Otro ausente, su fundamento inefable.

Los poemas más tempranos que se conservan de Fijman datan de alrededor de 1923, aunque solo cuatro se publicaran por aquel entonces y el resto debiera esperar hasta 2002 para ver la luz'. Esta producción inicial constituye el "umbral" del proyecto fijmaniano, ya que, si bien se destaca una notable variabilidad temática y se perciben lastres modernistas en el trabajo de renovación y flexibilización de metros y rimas tradicionales, así como en la búsqueda de la novedad expresiva y musical, se advierte ya la inquietud por el Otro que será vertebrador del lenguaje místico en versos como estos, por citar solo algunos: "Y clama en mi corazón / Un ansia de Dios" ("La buena soledad", vv. 9-10, 2005, p. 35); "Alegría de instintos! Yo medito / Que, cual zumo de Dios, tengo en mí mismo / Sabor y olor a

9 De las 21 piezas que Fijman envió en 1923 a Carlos Grunberg, editor de la revista Vida Nuestra, solo cuatro fueron consideradas para su publicación ("Resurrección”, “Hermana luz", "Impresión” y "Lamento indio"). El resto, descubierto casualmente por Eliahu Toker, recién aparecería en Hispamérica, en 2002. huertos de infinito" ("El sentido cardinal", vv. 6-8, 2005, p. 38); "Oh Señor, frente a las constelaciones, / Haz que pueda llorar / En una rara fiesta de visiones" (“Mar”, vv. 10-12, 2005, p. 44).

Si los Versos de juventud son el umbral, Molino rojo es el germen de la mística fijmaniana. En este libro, el primero y más popular de Fijman, el deseo del Otro se verifica, acendrado, no solo en lo que Arancet Ruda llamó "núcleo místico"10, sino también, y principalmente, en aquellos poemas que tematizan la locura, la soledad y el encierro. En tales composiciones, que alternan con otras de una religiosidad más manifiesta y aun con poemas descriptivo-impresionistas, la alteridad irreductible del Absoluto se traduce como amenaza y extrañeza, lo que puede leerse en la dificultad del hablante para asumirlo y reconocerlo. En este sentido, Michel de Certeau (2006), a partir de dos "relatos de locos", lee la locura como una "práctica de lo absoluto", esto es, como el desafío de aquel que se ha entregado por entero a lo Otro y, por consiguiente, se ha desligado de la institución, de la comunidad y aun del lenguaje concebido como contrato con los semejantes. Entonces, cabe pensar los poemas de Molino rojo en los que aparecen tematizadas la demencia y la soledad como modalidades tempranas (ausentes en los siguientes poemarios) del deseo del Absoluto, aunque esto no haga de tales composiciones piezas de lírica "mística”. Un buen ejemplo, además del tan mentado "Canto del cisne"11, es "Gabán", donde la locura aparece en el contraste entre el hablante y la multitud:

10 "Vísperas", “Mañana de sol”, “Ocasos”, “Crepúsculo”, “Ciudad Santa", "Toque de rebato" y "Cópula", cada uno de los cuales, según la investigadora, "representa un momento específico dentro de un proceso total, que muestra puntos de contacto con la mística y su expresión literaria" (Arancet Ruda, 2001, p. 25).

11 Se trata, sin dudas, del poema más conocido de Fijman (2005, pp. 61-62). En él, la locura es concebida, ya en los primeros dos versos, al mismo tiempo, como el "camino más alto y más desierto", esto es, como una senda que, aunque solitaria y amenazante, lleva a lo más elevado. El hablante aparece afligido y extraviado ("me hago la señal de la cruz a pesar de ser judío") frente a lo exterior, que se presenta de modo hostil; incluso "Dios", que surge como un opresor ("se acerca Dios en pilchas de loquero") y estrangula su garganta ("y ahorca mi gañote / con sus enormes manos sarmentosas"). El pedido del último verso (" ¡Piedad!") recalca el padecimiento del "yo" frente a la violencia absurda que lo rodea y resalta, asimismo, la naturaleza terminal del título, que, paradójicamente, es el primero del libro. 
Soy una alforja de lluvias.

Mi corazón regó en las primaveras

sementeras de espacio;

por eso mi cabeza

es una gorra remendada y parda

(genialidad)

o, un gabán roído,

pues he amado.

El pienso de mis días

desparramé en las sendas;

rompí todas las tejas

de los pesebres humanos.

De mal en peor

tildaron mi locura;

merma mi audacia,

enflaquecen mis manos dadivosas como las mulas viejas.

¡El gabán de mi ser se va pudriendo!

(Fijman, 2005, p. 97).

Si comparamos las dos primeras estrofas con las dos últimas, advertimos la condensación del malestar y la perturbación del hablante, que se presenta como el ausente en la multitud. Mientras que al comienzo recoge (alforja) la lluvia, que podría pensarse bíblicamente como el favor de Dios (Rivas, 2012, p.115), y fructifica, ama, siembra, dona y se eleva ("rompí todas las tejas / de los pesebres / humanos"), los dos primeros versos de la cuarta estrofa, que ilustran el aislamiento al que se ve sometido ("De mal en peor / tildaron mi locura"), señalan ya el desfallecimiento del hablante, y su gabán, que al principio remitía al amor y la genialidad, se trueca finalmente en la imagen de esa creciente angustia.

En Hecho de estampas, ya no es posible realizar, como en la producción anterior, una división temática: todo se reduce al deseo del hablante lírico, cuya interioridad constituye el espacio de enunciación ${ }^{12}$. Asimismo, las pocas notas referenciales - del pro-

12 De aquí que Barjarlía y Arancet Ruda hayan leído el segundo poemario, respectivamente, como una "noche oscura" (1992, pp. 159-164) y, de modo similar, como el "registro de una mutación interior" (2001, p. 162). pio "yo" y aun del mundo exterior- que podían identificarse en Molino rojo se pierden, y todas las composiciones -excepto la última, "Canción de cuna que no ha agradado a nadie", pieza que anticipa la repetición de Estrella de la mañana- llevan títulos numéricos. Esta concentración, la sinestesia ${ }^{13}$ como procedimiento que vertebra los poemas y el descentramiento del sujeto lírico ${ }^{14}$ hacen del segundo poemario la afirmación de la mística fijmaniana. Cito, a propósito, "Poema viII":

Cavar, cavar los ojos enarenados como se ahuecan los cuellos largos de los pozos cerrados en implacables soledades.

\section{Excavo la bienaventuranza} Cruzas llanuras

y acaecen palomas entre las manchas negras de las quejas. Siento en mis ojos las anguilas fuera de sí de los silencios montañeses

(Fijman, 2005, p. 128).

Aquí, los verbos "cavar" y "excavar" parecen señalar un proceso de interiorización del hablante (Arancet Ruda, 2001, pp.167-168), pero, al aparecer un "tú" en el verso cuarto, la acción se trueca en el deseo de una alteridad distante. En efecto, las "anguilas fuera de sí de los silencios montañeses" que siente - adviértase la sinestesia- el "yo" en sus ojos -órganos que es dable interpretar todavía como señales de interioridad- podrían pensarse como el doble carácter, al mismo tiempo terrible y glorioso del Otro, ya que la anguila, simbólicamente, en la tradición cristiana, condensa en sí a la

13 Sostenida sobre la disimilitud, que, en virtud de la tensión que genera, señala un más allá que, sin embargo, no dice. Por esto, puede pensarse que se relaciona estrechamente con el oxímoron, tropo que Certeau (2006) define como la unidad elemental del discurso místico. A propósito de él, señala el historiador francés: “Es un deíctico: muestra lo que no dice. La combinación de los dos términos suple la existencia de un tercero y lo presenta como ausente. Crea un agujero en el lenguaje. Talla en él el lugar de un indecible. Es un lenguaje que señala un no-lenguaje" (2006, p. 145).

14 Siguiendo a Zonana (2008), entiendo por "sujeto lírico" la correspondencia entre la voz que enuncia en primera persona y el paciente de la disposición afectiva, siempre que no haya una "modificación en la instancia del discurso" (p. 47). El "descentramiento" sería, entonces, la no correspondencia, que impide al lector identificar un sujeto. 
serpiente, usualmente de connotaciones negativas, y al agua, de sentido positivo (Chevalier, 2006). Eso se ve reforzado por "silencios montañeses", sintagma que aúna el silencio, que en las Escrituras suele aparecer como preludio de los grandes acontecimientos (Chevalier, 2006), y la montaña, lugar de contacto entre lo divino y lo humano donde estos usualmente tienen lugar.

Por fin, el proceso de concentración y pérdida de referencias alcanza su punto más hermético en Estrella de la mañana, último libro publicado de Fijman ${ }^{15}$. En este, el procedimiento de la repetición, de raigambre claramente veterotestamentaria, lo colma todo: el lenguaje estético que aquí se despliega remeda, formal y simbólicamente, el del Antiguo Testamento, primer monumento de la palabra divina que inaugura el poder-decir místico y, con él, la serie formal en la que se incardinaron los discursos místicos propiamente dichos (Certeau, 2006). Todo lo que remitía, en los Versos de juventud o Molino rojo, al mundo exterior se reduce ahora a un número limitado de símbolos, nombres y estructuras que se reiteran, con variaciones, en cada uno de los poemas. En "XIv", por ejemplo, hallamos:

Duermo bajo la estrella, mi estrella. Vísperas de la noche en luz donde comienzan los días y las noches a desmenuzar las tierras y los cielos

Amor, Amor, Amor.

Se levanta tu luz y el agua salta. Se levantan tus albas olorosas de suavidad profunda;

se levantan tus soles olorosos de suavidad toda crecida;

se levantan tus lunas olorosas de iluminada suavidad de niños;

y el agua salta albas, lunas y estrellas.

Saltan las albas, saltan las lunas y saltan las estrellas

(Fijman, 2005, p. 154).

15 Como en el poemario anterior, casi todas las composiciones llevan títulos numéricos. Aquí, de las 41 piezas, solo las últimas cuatro no lo hacen: "Adoración de los Reyes Magos", “Pampa de una noche y un día con su noche", “Canción de la visión real de la gracia" y "Canción de los ángeles de la muerte".
En línea con la interpretación tradicional del epígrafe bíblico que da título al libro ${ }^{16}$, y con la del otro pasaje del Apocalipsis donde aparece la "estrella (brillante) de la mañana" (Apc. 22, 16), el astro bajo el que duerme el hablante en el primer verso puede leerse como la anunciación de la Parusía (véase Rivas, 2012, p. 88), sentido que se ve reforzado por el sintagma "vísperas de la noche en luz" y por "luz", "albas", "soles" y "lunas", todo lo que remite a la luminosidad y al tránsito de la noche al día que señala, precisamente, la estrella. Nótese, a propósito, la repetición de los verbos ascensionales "levantarse" y "saltar", del adjetivo "olorosos", que apunta a la pureza y a las virtudes divinas (Chevalier, 2006, p. 813), y del sustantivo "suavidad", que subraya esos sentidos. La idea de un orden distinto y superior recorre todo el libro y oscila, en la figura de Cristo, que asume el lugar del Otro, entre la efectiva posesión y el deseo por lo inaprensible, que finalmente prevalece. Así, en la última pieza, "Canción de los ángeles de la muerte", hallamos:

Ángeles de la muerte preparan nuestra gracia y la vida y la muerte Ángeles de la muerte.

Ángeles de la muerte abrazan Dios y canto, y la vida y la muerte Ángeles de la muerte.

Ángeles de la muerte vísperas anunciadas de la vida y la muerte Ángeles de la muerte.

Ángeles de la muerte besan las albas albas por la vida y la muerte Ángeles de la muerte

(vv. 13-24, y 46-49, Fijman, 2005, p. 188).

16 et dabo illi stellam matutinam (Apc 2, 27-28). 
Esta letanía de 13 estrofas de estructura casi idéntica condensa, en el símbolo de los "ángeles de la muerte", mensajeros que anuncian el fin de la vida terrena y el comienzo de la divina, la cercanía del Otro. En Estrella de la mañana, entonces, el proyecto fijmaniano alcanza su lenguaje más característico en la mística. Ese deseo de Absoluto que se adivinaba tenuemente en los Versos de juventud coagula aquí el lenguaje por medio de la repetición y desorbita, como ya se advertía en Hecho de estampas, al hablante lírico, que, como toda otra nota referencial, se desrealiza.

\section{La transformación del proyecto estético}

Al estudiar la poesía fijmaniana dispersa conocida hasta el momento de la publicación de su tesis, Arancet Ruda (2001) señala cuatro rasgos unificadores. Primero, la mención de "cierto tipo formal de poema” (p. 445), generalmente popular y musical, en algunos títulos, lo que indicaría una voluntad ordenativa, aunque estas formas no estén efectivamente materializadas en los poemas que encabezan. Segundo, las referencias a lo pastoril, elemento de variados significados: por un lado, debido al particular "manejo de lo bucólico" (p. 465), evidenciaría la adscripción de esta producción a la vanguardia; por otro, el "afán utopista" de Fijman (p. 466). Tercero, la referencia a lugares geográficos, que siempre son presentados con "peso ontológico". Cuarto, la presencia de un tú femenino, "representación perceptible de un contenido que está más allá de lo estrictamente sensorial" (p. 517), que se identificaría con la Virgen María. Si bien comparto los tres primeros rasgos, no así las conclusiones biográficas a las que llega la investigadora. Al último elemento no lo considero una constante vertebradora ni unificadora, ya que su efectiva presencia a lo largo de los poemas dispersos y su significado resultan, a mi juicio, poco precisos y, por tanto, discutibles ${ }^{17}$.

17 Amén de las piezas en las que aparece un tú lírico explícitamente femenino - que no constituyen un grupo numeroso en el total de las recuperadas hasta hoy-, Arancet Ruda lo deduce en otros poemas dispersos a partir de ciertos rasgos que resultan inciertos y casi estereotipados: “la connotación desprendida de los motivos que lo rodean [al tú] (v.g. la luna, la flor, la niña)"; " el modo de pre-
Por mi parte, propongo dos características más, que Arancet Ruda sugiere, pero no como tales: la presencia de nombres propios y el estilo arcaizante. Los cinco atributos están presentes en la producción previa de Fijman, pero decididamente en menor medida $^{18}$. Su preeminencia en la poesía escrita en el hospicio puede interpretarse como la aparición de un trabajo retórico desusado hasta aquí y, al mismo tiempo, como una vuelta a la referencialidad, particularidades ambas que indican la ponderación de un pasado histórico o legendario.

A esto habría que agregar el uso reiterado del endecasílabo y del alejandrino (a veces, segmentado en dos versos), y de la rima consonante en forma de pareados sucesivos; ambos rasgos de notable presencia en el Libro de la cántiga de pasión (por ejemplo, en "Cántiga de bondad", "Cartofonía", "Cántiga de pasión", "Copla de mística experiencia”, "Égloga", "Eviternando"), sin que ello signifique un modelo fijo. En contraste, la notable presencia de la muerte, que ya hemos estudiado como una constante fijmaniana (Cárcano, 2011), refuerza los lazos con la obra anterior (particularmente, del recién referido poemario), no obstante la transformación operada en la poesía dispersa.

Los títulos que incluyen alguna forma poética tradicional son múltiples, y en todos los casos se trata de tipos líricos laxos y musicales ${ }^{19}$. Las formas

sentarse en el lenguaje (bastante ajeno a la estricta racionalidad)" o "la modalidad simbólica [...], aspecto femenino que atraviesa todos los poemas y en los distintos niveles presenta lo instintivo, que pone al sujeto en contacto con lo primario" (2001, p. 523). Aun si se asumiera esta presencia femenina, su identificación con la Virgen María parece todavía menos probada, hecho que la misma investigadora parece aceptar cuando afirma que "en muchos de los poemas el tú es María, aunque no en todos contamos con señas de identidad suficientes" (2001, p. 519).

18 Ejemplos de ello son, entre otros, "En muy añeja fabla castellana...", "La aldehuela de vuelta y media", “Canción de cuna que no ha agradado a nadie", "Canción de los ángeles de la muerte", "Imitación de San Antonio de Areco".

19 "Canción de la doctora del anillos de jaspe", "Canción para la niña prosa de la cruz", "Romance de la ausencia", "Romance de nombradía", "Égloga concreta que sustenta la abstracta belleza de las cosas, para el místico doctor San Juan de la Cruz", "Canción de pueblo y de senado", "Canción en dogma regular de Cristo", “Égloga común”, “Romance lunar", “Letanía del buen uso", “Copla trascendente, o divina relación para tórculos de Castilla la Vieja", "Égloga de bodas", "Égloga de Castilla", "Canción para la bella sor María de Ágreda", "Canción de manos taciturnas ocupadas 
tradicionales también reenvían a lo conocido $y$, de algún modo, a un pasado: se trata, en todos los casos, de tipos líricos desusados o poco comunes

de muerte", “Cántico trascendente”, “Relación de elegía”, "Balada para el sueño de las tardes", “Cántigas", “Canción con algo de canción y soledad y yermo", “Canción que nace en cielos y torres y niñas cercanas", “Cántica a la virgen”, “Cántica a Sancta María", "Cántica a sor Gregoria de Santa Teresa", "Madrigal de Occidente", "Madrigal de la tropa argentina", “Canción a una nieta en los cielos de Francia", "Canción para la niña que se llamaba Nora", “Canción en las Indias occidentales", “Canción de orden mundano", "Canción de encartamiento", "Canción de los dos hombres", “Cántica sucesiva", “Romance de énfasis", “Canción del estanquero", "Canción india de mística teología”, “Canción india de tibias calladas", "Romance del vértigo perfecto", "Romance de Castilla”, "Canción dactílica", “Canción de las cosas arduas", "Canción de Juan doctor", "Balada en exasílabos de negros y pardos, de pardas y negras", “Canción al lavador del sueño y de la tarde", "Letanía de la tarde en un viejo estampario", “Loa a doña beata soledad de la pasión y muerte", "Romance en veinte de menor cuantía para Nuestra Señora [.] Letanía apostrofia", "Canción de florista", “Écloga”, “Eclogario", “Cantiga del afecto", “Cantiga de la pasión", “Cantiga suplicante", “Canción de soledad y soledad”, "Canción de la mar en la mar", “Coplas de rey”, “Canción de la mujer que tiene vara", "Canción no tmetopsíquica de doña Remedios de la Flor en las Indias occidentales" y "Canción de arroz y trigo y primavera", “Canción a la mujer más negra de la aldea", “Canción a la mujer de muerte", “Canción del que no puede llorrar” (así escrito en el original), “Cántiga de bondad”, “Cántiga de pasión", “'Canción especial para la niña pobre", “Canción de niños y las cuatro muertes", "Canción de mar", “Beato madrigal”, "Romancillo para Inés", "Copla de gloria", Romance de serenas cosas", "Copla de mística experiencia”, “Égloga”, “Madrigal de razón y soledad”, “Cántiga de los pinos", "Romance del saber. De soledad y muerte", "Canción del rey sucio", “Canción de doce ermitas y una sierva”, “Con alguna intención de elegía", "Romance de tres lugares" y "Madrigal con la hermana pobreza". Arancet Ruda afirma que, "al menos con la connotación de una medida - si no con su realización-, las formas tradicionales remiten a un orden" (2001, p. 445). Coincido con esta apreciación, que se ve reforzada en otros títulos que, aunque no aluden a composiciones poéticas, sí remiten, de algún modo, a una forma, a un patrón o a un orden, muchas veces vinculado con lo literario, lo musical o lo devocional: "Confíteor", "Epístola rural", “Polifonía”, “Canon", “Cuento de Sheherazad”, "Muy beata política beata", “Epístola a Favonio", “Gramática de estrellas fijas”, “Verso polimorfo", “Epílogo del ángel o la flor", “Decreto", “Baile", “Arte retórica de trueque", "Política beata del sentido y la gloriosa mente en la pobreza", "Pantomima analógica", "Historia de una imagen seglar y no seglar", "Seráfica cosmogonía", "Retrato de doctor", "Carta de niñas a merced de estrellas", "Arsis y tesis", "Canon de mística teología" (tachado en el manuscrito original), "Términos de blasón”, “Blasón de Arcángel”, “Ética”, “Viernes Santo" y “Cartofonía". Esta idea de orden, que contradice la tesis que amalgama demencia y creación en Fijman, se vio reforzada por la reciente aparición del Libro de la cántiga de pasión, conjunto de 38 poemas compuestos, según María Teresa Dondo, entre 1952 y 1962, aunque ninguno fechado (salvo "Piscomotora", donde O. H. Dondo anotó "1960"). Estos habían sido legados, para su publicación, por Fijman a su amigo Osvaldo Horacio Dondo, entonces director general de Bliotecas y Publicaciones Municipales de Buenos Aires, poco antes de la muerte de este último, en noviembre de 1962, hecho que truncó el proyecto. para el momento en el que Fijman escribía, pero notablemente populares, por ejemplo, en el Siglo de Oro español. Es el caso del madrigal, composición popular de forma métrica variable, pero generalmente concebida como una combinación libre de versos heptasílabos y endecasílabos, usualmente rematada por rimas pareadas, de tema amoroso, expresión sencilla y referencias al mundo pastoril (Baehr, 1973, pp. 402-407). Fijman tituló, al menos, cinco de sus piezas como madrigales: "Madrigal de occidente"20, "Madrigal de la tropa argentina"21, "Beato madrigal", "Madrigal de razón y soledad" y “ Madrigal con la hermana pobreza"; los últimos tres sin fecha. Cito el primero:

Una razón de voces agítase en los cerros de los valles austeros.

Ah mujer implacable de luz y de mañana ya balaron los ríos en la muerte lejana.

Una razón de voces se pone en occidente. Cayeron los rebaños,

las mieses y las tierras y los años

y la luna más grande con la luna candente

(Fijman, 2012, p. 28).

Este madrigal, casi una estampa campestre, concuerda en buena medida con la definición más corriente, aunque aquí se emplean versos de catorce sílabas en lugar de once.

La referencialidad difusa que construyen los títulos en los que aparecen formas poéticas que no están materializadas en los poemas se concreta algo más en los topónimos, que remiten, casi siempre, a lugares con un pasado célebre: Lutecia y "la Seine", Lieja, Roma y el Tíber, Etruria, Cilicia, "Cana de Galilea"22, Toledo, Córdoba, Jerusalén, Francia, España, las Indias Occidentales y Castilla, a veces seguida por los sintagmas "la Muerta" o "la Vieja". Esta región es la más nombrada y considerada de todas como paradigma de la antigua armonía entre Estado y fe. Teniendo esto en cuenta, en una

20 Fechado el 11 de octubre de 1957.

21 Fechado el 18 de octubre de 1957.

22 Escrito sin tilde en el manuscrito original. 
composición de difícil lectura como es "Canon"23, podríamos pensar que la imposición de la fe católica está positivamente connotada:

Castilla parte en cruz las aldeas y torres, los versos y los llanos.

El Cid cabalga en cruz;

y los siervos blasfeman con la sangre de Cristo.

Los molinos se tornan por un tiempo de muerte;

y Don Miguel Cervantes redime los cautivos con ayunos y prosas consonantes.

Castilla dice el Canon en la sangre judía de los niños judíos;

y las torres malditas de las viejas aldeas asesinan en cruz a los siervos y llanos

(Fijman, 2005, p. 211).

La figura del Cid, asociado épicamente a la Reconquista, aparece como paradigma de coraje y de virtud ("cabalga en cruz"), lo que contrasta con los "siervos" - posiblemente, los mudéjares- que "blasfeman con la sangre de Cristo". De modo análogo, Cervantes, "redime a los cautivos" - seguramente, como él, de los musulmanes-, al tiempo que los "molinos se tornan por un tiempo de muerte". Por su parte, Castilla "dice el Canon en la sangre judía / de los niños judíos". Resulta difícil decir si con "Canon" se refiere aquí la parte central de la misa, el canon bíblico, el canon XIV decretado por el III Concilio de Toledo ${ }^{24}$ - que reglamentaba, entre otras ordenaciones, que los niños judíos podían ser separados de sus padres para ser educados en la fe cristiana - o sencillamente al credo católico, que se impuso, forzosamente, a muchos judíos hispanos con posterioridad al decreto de expulsión de los Reyes Católicos. Sin embargo, no se advierte una carga peyorativa asociada a la región que los monarcas rigieron. Las menciones de Castilla se reiteran insistentemente en la poesía escrita en el hospicio,

23 Fechado el 28 de noviembre de 1962.

24 Este congreso, celebrado en el año 589, tuvo como marco la conversión del rey visigodo Recaredo I, por lo que es visto como la más temprana unión de fe y monarquía en tierra hispana. asociadas a la devoción, la soledad, la pobreza, la sencillez, la aridez de su paisaje.

En la misma línea que los topónimos, pero quizás en un grado mayor de concreción, están los nombres propios, que contribuyen igualmente a la referencialidad ponderativa del pasado de la que hablé antes, ya que se trata, casi en la totalidad de los casos, de personajes - históricos, ficcionales o míticos- que aluden a tiempos remotos o legendarios. La mayor parte pertenece al mundo hispánico: "Don Miguel Cervantes" (1547-1616), San Juan de la Cruz (1542-1591), al que quizá también se refiere el sintagma "Juan doctor"; "Felipe", evidentemente, Felipe II (1527-1598); Sor Gregoria de Santa Teresa (1653-1736), monja y poeta andaluza; sor María de Ágreda (1602-1665), abadesa y escritora mística castellana que mantuvo correspondencia con el rey Felipe IV; Juan II de Castilla (1406-1454), "el Cid", personaje épico inspirado en la figura del caballero Rodrigo Díaz de Vivar (1048?-1099), y “el Quijote”. Otros tantos provienen de la historia o la mitología romana: Favonio, Quirinus, Tutela, Numeria, "Eneas de Venus", "Rómulo de Marte", Lavinia, Volumnia y "Pretexta, senadora", nombre latino este último que no parece aludir a una figura histórica concreta. Solo aparecen un par de personajes de la mitología griega y uno de la literatura árabe, dos de los cuales están escritos de modo peculiar: la "Esfinge de caminos", "Iphigenia", escrito como en latín o castellano antiguo, y "Sheherazad", grafía que parece emular la pronunciación en lengua farsi. También hallamos una única figura semítica: Dimas ${ }^{25}$, tradicional-

25 También existe un Dimas griego: “Dimas (griegos).--Rey de Tracia, padre de Hécuba, mujer de Príamo" (Sechi Mestica, 2007, p. 75). Sin embargo, aunque escasamente inteligible, el poema en el que aparece ese nombre remite casi indudablemente al "buen ladrón". Para sostener esto, nos apoyamos en la aposición explicativa de "Dimas" que aparece en el título, "monoclepto", y en los primeros versos: "Tú robabas la muerte / de la flor en la rosa, de la flor en el sueño" (vv. 1-2, 2012, p. 43). Sobre el Dimas semítico existen dos leyendas. La primera dice que, "[c]uando José y María iban con el Niño hacia Egipto, fueron asaltados por unos ladrones. Uno de sus jefes quería matarlos inmediatamente para robar su reducido equipaje. Pero algo acerca del Niño Jesús penetró en el corazón de Dimas, que era uno de aquellos ladrones. Él impidió que se les hiciera ningún daño a Jesús y a Sus padres [...]. Y la leyenda dice que Jesús y Dimas se encontraron otra vez en el Calvario, y Dimas encontró en la cruz el perdón y la misericordia para su alma y la seguridad de la Salvación". La segunda leyenda, una variante de la 
mente asociado al "buen ladrón” bíblico. Por último, encontramos cuatro nombres cuyo referente resulta desconocido: "la niña que se llamaba Nora", "doña Remedios de la Flor" y "sor Natividad"26, a quien se menciona en "Speculum deitatis" y la "Inés" del "Romancillo para Inés".

Históricos o ficticios, los personajes que aparecen en la poesía escrita en el hospicio están trazados con pocos elementos que permitan reforzar las características con las que la tradición los ha registrado ${ }^{27}$. Por último, cabe señalar que existe un poema sin fecha en cuyo título se incluye el nombre de un buen amigo de Fijman, "Problema de Osvaldo Horacio Dondo", reproducido como anexo del Libro de la cántiga de pasión, pero que no forma parte del conjunto.

Si los títulos que incluyen formas poéticas tradicionales, los topónimos y los nombres propios configuran una referencialidad que, aunque difusa, era hasta aquí impensada en la lírica fijmaniana, los elementos que remiten a lo pastoril son, en este sentido, más difíciles de calibrar. Aun así, es posible conjeturar que este imaginario remite, por una parte, a los siglos XV y XVI, es decir, el momento en el que el género consiguió su más alto grado de popularidad y formalización en la tradición castellana; por otra, a un tiempo legendario propio de lo pastoril.

anterior, "es aún mejor conocida en España, porque se encuentra en el Libro dels Tres Reis d'Orient[...]. Cuenta esa variante que, cuando iba huyendo de Belén a Egipto, la Sagrada Familia fue apresada por dos bandoleros; el uno era cruel, y quería matar al Niño Jesús; y el otro, compasivo, que Le salvó la vida e invitó a la Sagrada Familia a pasar la noche en su cueva. La mujer de este 'buen ladrón' le cuenta a María que tiene un hijito recién nacido que está leproso. María lo baña en la misma agua en la que ha bañado a Jesús, y el niño queda sano y limpio. Pasado el tiempo, en el Calvario, el hijo del ladrón alevoso muere a la izquierda de Jesús, y el del compasivo, a la derecha, y este fue el que pasó al santoral de la Iglesia Católica sencillamente como el 'buen ladrón', aunque diversas tradiciones lo llamaron Dimas, Dismas o Dimsas" (Barclay, 2006, p. 22). Hay que agregar aquí que "Dimas" era también el apodo del padrino de bautismo de Fijman, José Luis Antuña Gadea (1894-1968).

26 Según escribe Bajarlía, Zito Lema le refirió que esta última fue una monja francesa que, luego de haber leído el número homenaje de la revista Talismán, le habría escrito a Fijman, desde Sceaux, el 28 de mayo de 1969: "leo su poema Canto del cisne... la palabra Desierto me habla, usted la nombra muchas veces. Hay tanta soledad o, al menos, me parece a mí descubrir tanta soledad y silencio abismal en sus versos... tanta ique a pesar de la primavera de Europa, tengo frío!" (citado por Bajarlía, 1992, p. 191).

27 “Iphigenia", que bien ha estudiado Arancet Ruda (2001, pp. 499-500), es una de las pocas excepciones en este sentido.
Ambas temporalidades, no obstante, su distinta naturaleza, connotan un pasado positivamente valorado, aunque el segundo caso sea una edad dorada sin determinaciones contextuales precisas. Como escribe Arancet Ruda (2001, pp. 253-264), si bien los títulos en los que aparece alguna denominación compositiva pastoril no son más que unos pocos, aquellos elementos asociados al género están dispersos también por otros poemas. Por ejemplo, "Escénica"28:

Ahora saltas, niña, por partes el aldea definiendo su nombre,

las nueces, los almendros y las torres.

Balaron las ovejas

y las nubes empiezan en la fuga del agua.

Vamos contigo del aldea á la aldea con pájaros y tierras.

Una palma declinas, una torre, una espiga, dos bueyes,

y los nombres que tocan paciencia de azahares, la lluvición, la soledad, la muerte

(Fijman, 2005, p. 270).

No creo que este imaginario pastoril pueda explicarse por los afanes utopistas de Fijman. Igualmente, según dije antes, en la poesía escrita en el hospicio, hay una consideración positiva del pasado, histórico o legendario, que se consigue a través de distintos dispositivos que conforman una referencialidad particular. A esta también contribuye un particular trabajo retórico signado por el empleo de arcaísmos, latinismos, tecnicismos y neologismos. Entre los primeros, hallamos: "las harmónicas nubes" ("Prospectiva"29, v. 3, 2014, s/p); "Contemplamos los bosques en la belleza harmónica" ("Canción de los dos hombres" ${ }^{30}$, v. 6, 2012, p. 53); "en cuyas manos son las cosas abscondidas" ("Versecillos de Castilla la Muerta" 31 , v. 2, 2005, p.212); "los limones Asyrios" ("Epístola rural"32, v. 2, 2005, p. 221); "aún los mediodías, qual

28 Sin fecha.

29 Fechado el 26 de noviembre de 1957.

30 Fechado el 26 de diciembre de 1957.

31 Fechado el 1 de enero de 1963.

32 Fechado el 12 de abril de 1964. 
de estrellas" ("Canción para la bella sor María de Ágreda"33, v. 7, 2005, p. 236); "el que antes habías la misma flor" ("Con castillas de antes, con Castilla la Vieja" ${ }^{34}$, v. 3, 2005, p. 237); "Felipe escribe en tablas su voluntad católica harmoniosa" ("Solar de la raza”, v. 4, 2012, p.17); "Quando andaba Castilla" ("Romance de la nombradía”, v. 1, 2005, p. 218); “Quando nasca tu hijo” (“Canción de pueblo y de senado"35, v. 10, 2005, p. 223); "y las cabras fetosas" ("Romance de serenas cosas", v. 2, 2019, p. 46). Además, habría que incluir aquí el título “Cántica a Sancta María” (2012, p. 26). Arancet Ruda también considera "pábulo" y "dotal" "Urbs antiqua fuit”) como arcaísmos (2001, p. 482), pero estos no son definidos de tal modo por el Diccionario de la Real Academia Española. Se trata, más bien, como el caso del título "Écloga" y las siguientes voces, de términos desusados o poco frecuentes: "que el amor de la paz ocupa álos querubes" ("Prospectiva”, v. 4, 2014, p. s/p); "y tú querub de los querubes" (“Égloga”, v. 3, 2019, p. 50); "y su algo eviterno de celeste bondad" ("Gramática de estrellas fijas"36, v. 5, 2005, p. 231); "amándose eviternan la pobreza” (“Eviternando”, v. 6, 2019, p. 54); “Tú que vuelves por lágrimas el evo del arcángel y la rosa" ("De mística teología”" v. v. 1, 2005, p. 232); "binas y primaveras, ser de campos, de estrellas" ("Copla trascendente, o divina relación para tórculos de Castilla la Vieja”, v. 8, 2005, p. 233); “allegamos a Castilla” ("Égloga de Castilla" 38 , v. 8, 2005, p. 235); "y la ciudad infusa de la luz y su canto" ("Solsticio de verano"39, v. 4, 2005, p. 238); "La piedra sanguinosa en tiempo de muralla"

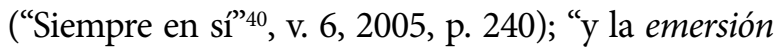
lunar en canónicos vientos" ("Loa a doña beata soledad de la pasión y muerte”41, v. 3, 2005, p. 256); “incorporal y vieja” ("Donaria”'2 , v. 8, 2005, p. 259); "para un sueño odorante" ("Romance en veinte de menor cuantía para

33 Fechado el 21 de diciembre de 1965.

34 Fechado el 25 de diciembre de 1965.

35 Fechado el 1 de junio de 1964.

36 Fechado el 14 de septiembre de 1965.

37 Fechado el 8 de diciembre de 1965.

38 Fechado en 1965.

39 Fechado el 27 de diciembre de 1965.

40 Fechado el 14 de marzo de 1966.

41 Sin fecha.

42 Sin fecha.
Nuestra Señora [.] Letanía apostrofia"43, v. 6, 2005, p. 260); "sobre el impar concluso de virtud y de esencia" ("Lutecia" ${ }^{4}$, v. 2, 2005, p. 262); "y tus botas bailaban los afanes moceros" ("Canción para la niña que se llamaba Nora" ${ }^{\prime 4}$, v. 10, 2012, p. 37). Nótese, al respecto, que muchos son cultismos, es decir, más cercanos al étimo latino que las palabras tradicionales. Los latinismos propiamente dichos, por su parte, aparecen siempre en los títulos: "Janua caeli" ('puerta del cielo'), "Confíteor" (castellanización de confiteor, 'yo confieso'), “Urbs antiqua fuit" ("Una ciudad antigua hubo", comienzo del verso 13 del libro I de la Eneida), "Speculum deitatis" ('espejo de Dios'), “Donaria” ('altar, templo, ofrenda'), "Aetas magna" ('gran edad'), "Sapiens injure"46. Arancet Ruda (2001, p. 454) incluye también, en este grupo, el adjetivo "incóndita"47, que aparece en "Écloga".

El lenguaje arcaizante de gran parte de los poemas escritos en el hospicio demuestra, como queda dicho, un evidente afán retórico que no se advertía en los poemarios publicados y que recuerda, por momentos, a los Versos de juventud, aun anclados a ciertas formas modernistas. Índice de esta nueva pretensión son también los tecnicismos y neologismos de algunas composiciones. Entre los primeros, están los títulos "Ansomnia ${ }^{48}$ perfectísima", "Anafonesis"49, "Estereognóstica" ${ }^{50}$ y "Pneumatológica" ${ }^{1}$, "Psico-

43 Sin fecha.

44 Sin fecha.

45 Sin fecha.

46 Probablemente fuera in jure, con lo cual la traducción sería 'sabedores de derecho', fórmula que aparece en la ley XIII, título IV, de la III de las VII partidas de Alfonso X.

47 'Sin enterrar, confuso, desordenado, irregular, tosco, sin arte'. Del latín inconditus, $-a$, -um.

48 'Pérdida de sentido del olfato'. Del latín científico anosmia, y este del griego ớv- an-, 'an-', óouń osmế, 'olor', y el latín -ia, '-ia'.

49 'Elevación de la voz', 'entrenamiento para fortalecer la voz y el

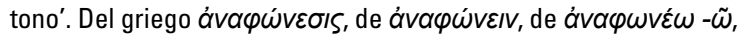
'llamar en voz alta'.

50 "Estereognosis": 'Conocimiento de un objeto y sus cualidades

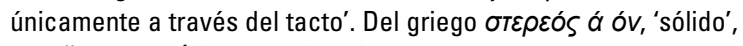

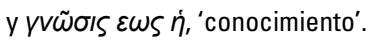

51 'Estudio del espíritu'; 'doctrina católica del Espíritu Santo'.

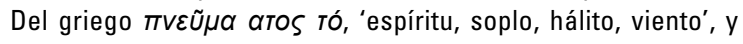
-^oyía -logía, '-logía'. 
somática"52, "Pantofóbica"53 y "Psicomotora"54 y los siguientes versos: "tartamudeando cosas dehiscentes" 55 (“Alabanza de señoríos"56, v. 4, 2012, p. 31); "con los siglos perclusos"57 ("Canción a una nieta en los cielos de Francia" 58 , v. 6, 2012, p. 35); "fugas astenópicas" 59 ("Tú la mujer de nubes y suspiros..."60, v. 2, 2012, p. 45). En cuanto a los neologismos - a veces más osados, a veces menos-, se hallan en el título "Canción no tmetopsíquica ${ }^{61}$ de doña Remedios de la Flor en las Indias occidentales" y en algunos otros versos: "sinrazón, indistante, / la simplición harmónica beata, / sinfigura, beata" ("Muy beata poética beata"62, vv. 7-9, 2005, p. 210); "en la lución beata de los cirios" ("Versecillos de Castilla la Muerta", v. 10, 2005, p. 212); "la arboreidad de sombras emanan en tu canto" ("Égloga concreta que sustenta la abstracta belleza de las cosas, para el místico doctor San Juan de la Cruz"63, v. 4, 2005, p. 219); "y el ciprés concorpora la más alta tristeza" (“Epístola rural”, v. 3, 2005, p. 221);

52 Que afecta a la psique o que implica o da lugar a una acción de la psique sobre el cuerpo o al contrario'. De la conjunción de psico-, del latín psycho-, y este del griego $\psi$ uXo-, 'alma o actividad mental',

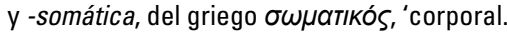

53 Perteneciente o relativo a la pantofobia, 'miedo a todo'. Del griego $\pi \alpha v т \alpha$, 'todo, en todo momento', $y$ del sufijo -fobia, del griego $\varphi \circ \beta ı \alpha$, 'rechazo o aversión'.

54 Perteneciente o relativo a la psicomotricidad, 'motilidad de origen psíquico, integración de las funciones motrices y psíquicas', del latín psycho-, y este del griego $\psi$ uXo-, 'alma o actividad mental', y motricidad, del francés motricité, 'capacidad de un cuerpo para moverse'.

55 'De pericarpio que se abre naturalmente para que salga la semilla'. Término propio de la botánica, dicho de un fruto.

56 Fechado el 18 de octubre de 1957.

57 'Que no tiene posibilidad de realizar movimiento alguno'. Término médico derivado del latín præclūsus, participio pasado de præclūdo, 'cerrar, atrancar, taponar, obstruir, impedir'.

58 Fechado el 11 de noviembre de 1957.

59 "Astenopía": 'debilidad o fatiga de los ojos'. Término médico derivado

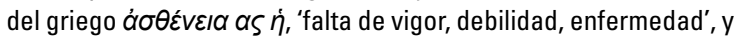

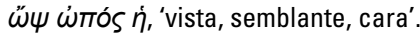

60 Fechado el 11 de diciembre de 1957.

61 En Romance del vértigo perfecto, este adjetivo aparece como tnetopsíquica, pero, al ver el facsímil que figura en el libro, en el que no es posible distinguir nítidamente si se trata de una $n 0$ de una $m, y$ al no ser posible hallar el elemento compositivo tneto- en castellano, latín o griego, creemos que lo correcto es tmetopsíquica,

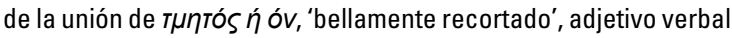
de T⿱㇒́ $\mu v o$, y del latín tardío psychǐcus, 'perteneciente al alma animal o natural', y este del griego భUXIKóS ń óv, de igual significado.

62 Fechado el 26 de noviembre de 1962.

63 Fechado el 6 de diciembre de 1963.
"Etruria pantomima. / Los lidos y curetas pantomiman la danza / de ciclos y de vientos / con perlúcidas noches" ("Epístola a Favonio"64, vv. 6-9, 2005, p. 222); "sobre el no ser más puro del empíreo beado" ("Flor de santidad"65, v. 12, 2005, p. 227); "Lunador, cuatro lunas / han lunado los cielos" ("Romance lunar"66, vv. 1-2, 2005, p. 229); "el vespertino celestiar" (“Siempre en sí", v. 4, 2005, p. 240); “Tú, citante de sueños, lucidante" ("Sapiens injure"67, v. 4, 2012, p. 89); "la lluvición, la soledad, la muerte" ("Escénica", v. 12, 2012, p. 270); "Éste aquí, seráfico leyente" ("Retrato de doctor"68, v. 1, 2005, p. 267); "teoplasma de arcángel" ("Metasomática”69, v. 6, 2015, p. 17); "las albas y deuterias" ("Eclogario"70, v. 6, 2005, p. 268); "cománticas de números y guerras" ("Problema de Osvaldo Horacio Dondo", v. 10, 2019, p. 100); "la tarde viene con las cabras / excurvadas de nubes" ("Égloga", v. 2, 2019, p. 50); "el amor eternando de belleza" (“Cántiga de bondad", v. 8, 2019, p. 30); "la armónica paloma eternará la melódica ciencia" ("Cartofonía", v. 2, 2019, p. 31). A propósito de este último poema en el que aparece "eternar", cabe decir que su título probablemente derive analógicamente de "cartografía", como si se tratara con "Cartofonía" del 'arte de trazar mapas sonoros'. Otro título, "Helcópodoe”, resulta más oscuro. Quizá tenga alguna relación con la "marcha

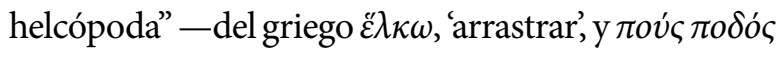
$\delta$, 'pie'- o "marcha de Todd", afección por la que un miembro inferior paralizado es arrastrado, sin conocimiento consciente del propio paciente, como si fuera un cuerpo extraño. Otro término poco decodificable es el del encabezado "Dimas, monoclepto". Resulta evidente que el neologismo responde a la unión de las partículas mono-, 'uno, 'único,' y clepto-, 'robo', pero no resulta fácil decir cuál sería el significado preciso de esta aposición. Por su parte, "metasomática" y "metalógica", términos que inspiraron a los editores de Metapoemas para elegir el título del libro, resultan más

64 Fechado el 28 de mayo de 1964.

65 Fechado el 28 de octubre de 1964.

66 Fechado el 24 de mayo de 1965.

67 Sin fecha.

68 Sin fecha.

69 Sin fecha.

70 Sin fecha. 
transparentes, ya que derivan de la unión del elemento compositivo meta- - 'junto a', 'después de,' 'entre,' 'con' o 'acerca de'- y los adjetivos somática, ca, 'perteneciente o relativo al cuerpo', y lógico, ca, 'perteneciente o relativo a la lógica o al pensamiento en general'. Estos neologismos, creados, como los tecnicismos, a partir de raíces griegas o latinas apuntan también, por estas mismas, a la configuración de un lenguaje arcaizante.

\section{A modo de conclusión}

En la poesía compuesta en el hospicio, el proyecto fijmaniano que comenzó a gestarse en los Versos de juventud y alcanzó su lenguaje más característico en la mística de los últimos dos libros, aparece transformado. Con todo, en contra de lo que usualmente se piensa, aquí se puede advertir que Fijman no abjuró de todo principio estético: su producción tardía está vertebrada por un rasgo saliente que determina una referencialidad y un trabajo retórico nuevos: la ponderación del pasado. El porqué de esta mutación es difícil (si no imposible) de identificar: la prolongada estancia de Fijman en el hospicio probablemente haya influido de algún modo en este paso del hermetismo y la concentración a una cierta dispersión o apertura, pero esta conjetura no puede más que ser eso. En cualquier caso, allende estas suposiciones, lo cierto es que, transfigurado, el proyecto fijmaniano progresó hacia nuevas formas, distintas del modo místico, pero tan marginales como él: la difusa referencialidad de la poesía escrita en el hospicio y el lenguaje arcaizante que la acompaña siguen alejados de las estéticas imperantes en el período que va de los años cuarenta a fines de los sesenta. $\mathrm{Y}$ es que, como dice Reynaldo Jiménez en un texto sobre Romance del vértigo perfecto, “... la poesía de Fijman, la antes publicada como obra completa y la que ahora se nos descubre, en toda su incompletud (y la nuestra), [...] ha sido en todo momento una rareza" (2012, p. 63).

\section{Referencias}

Acta Policial. Comunicación de la Internación (mayo de 1969). Talismán, 1(1), 9.

Arancet Ruda, M A. (2001). Jacobo Fijman. Una poética de las huellas. Buenos Aires: Corregidor.

Arancet Ruda, M. A. (2014). Viel, así en el cielo como en el canon: un lugar en el corpus de la poesía argentina. Letras, (69-70), 9-34.

Baehr, R. (1973). Manual de versificación española. Madrid: Gredos.

Bajarlía, J. J. (1992). Fijman, poeta entre dos vidas. Buenos Aires: Ediciones de la Flor.

Barclay, W. (2006). Comentario al Nuevo Testamento. Viladecavalls: Editorial Clie.

Cárcano, E. (2011). Hacia la Nada Absoluta: la muerte y la noche como simbólicas cardinales de la expresión mística de la poesía de Jacobo Fijman en el período 1931-1970. Gramma, XXII (48), 122-142.

Cárcano, E. (2017). "Con los ojos en la noche": la poesía "mística" de Jacobo Fijman en los márgenes. Buenos Aires: Universidad del Salvador. Tesis doctoral inédita.

Certeau, M. de (2006). La fábula mística. Siglos xvi-xvii. Madrid: Siruela.

Chevalier, J. (1986). Diccionario de los símbolos. Barcelona: Herder.

Fijman, J. (1926). Molino rojo. Buenos Aires: Talleres Gráficos El Inca.

Fijman, J. (1929). Hecho de estampas. Buenos Aires: M. Gleizer Editor.

Fijman, J. (1931). Estrella de la mañana. Buenos Aires: Número Editorial.

Fijman, J. (2005). Obras (1923-69). 1: Poemas. Florida, Buenos Aires: Araucaria.

Fijman, J. (2012). Romance del vértigo perfecto. Buenos Aires: Descierto.

Fijman, J. (2014). Ocho poemas manuscritos. Madrid: Del Centro Editores.

Fijman, J. (2015). Metapoemas. Buenos Aires: Ediciones Kalos.

Fijman, J. (2019). Libro de la cántiga de pasión. Buenos Aires: Editorial Duino.

Jiménez, R. (2012,). Vértigo perfecto en oficio de trazar, la poesía de Jacobo Fijman. Agulha. Revista de cultura, (3), 61-68. 
Universidad Pedagógica Nacional

Facultad de Humanidades

Jitrik, N. (1998). Canónica, regulatoria y transgresiva. En Cella, S. (comp).. Dominios de la literatura. Acerca del canon (pp. 19-41). Buenos Aires: Losada.

Rivas, L. H. (2012). Diccionario de símbolos y figuras de la Biblia. Buenos Aires: Amico.

Sechi Mestica, G. (2007). Diccionario Akal de Mitología Universal. Madrid: Akal.
Toker, E. (2002). Jacobo Fijman. Hispamérica. Revista de Literatura, (93), 49-64.

Zonana, V. G. (2008). La conformación subjetiva en el poema: variables, niveles y perspectivas de análisis. Signo \& Seña, (19), 33-66. 